\title{
Pedagogía de la Comunicación Estratégica: una experiencia en construcción
}

\author{
Analía Chiavassa - Romina Trincheri \\ UNIVERSIDAd NACIONAL dE ROSARIO \\ anachiavassa@gmail.com / rotrincheri@gmail.com
}

\begin{abstract}
Resumen
El artículo recupera la experiencia pedagógica del Seminario Gestión de la Comunicación Estratégica en la Organizaciones de la Facultad de Ciencia Política y Relaciones Internacionales de la Universidad Nacional de Rosario durante más de 15 años de práctica, haciendo foco en las lecciones aprendidas y los nuevos interrogantes y desafíos en la complejidad de los escenarios actuales.

Palabras clave: Comunicación Estratégica, Sentido, Diversidad

Resumo

O artigo traz a experiência pedagógica do Seminário de Gestão Estratégica da Comunicação em Organizações da Faculdade de Ciências Políticas e RRII da Universidade Nacional de Rosario por mais de 15 anos de prática, focando nas lições aprendidas e as novas questões e desafios na complexidade dos cenários atuais.

Palavras chaves: Comunicação Estratégica - Sentido - Diversidade
\end{abstract}

\section{Introducción}

El Seminario surge como una respuesta a una problemática específica planteada en los debates del cambio del plan de estudio de la Carrera de Comunicación Social en el año 2001 donde fueron anuladas las orientaciones (comunicación masiva y comunicación institucional) para pasar a una única titulación común.

En dicho momento se intentó pensar en una materia optativa que nucleara los contenidos específicos de la comunicación institucional y que intentara profundizar sobre la gestión de la comunicación en las organizaciones desde la perspectiva estratégica. 


\section{VREVCom \\ REVISTA CIENTIFICA DE LA REDCOM}

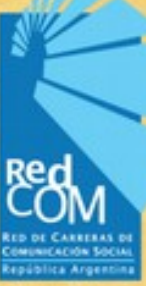

REVCOM | ISSN 2451-7836 | Año 4, \#8 | mayo de 2019 | Dossier temático | e004

El desafío inicial era poder construir un espacio de aprendizaje no tradicional que no se estructurara en teóricos y prácticos sino en una suerte de laboratorio donde pudieran utilizarse como caja de herramientas distintas categorías fundantes de la comunicación, trabajadas en otras asignaturas tales como Lenguajes y Teoría de la Comunicación, Teoría Política. En este sentido se pensó en un seminario anual, de dos horas semanales que fuera problematizando por temas problemas de gestión, proponiendo líneas de abordaje y rescate de miradas teóricas sobre los mismos. Esta cuestión requirió proponer entre las bases del programa un pacto entre los docentes y estudiantes donde explícitamente se comprometieran con la participación activa en las clases a través de interrogantes, exposición de temáticas actuales, etc. En este sentido la propuesta metodológica incluyó la utilización de gabinetes en situación en el espacio áulico, en pos de desarrollar un entrenamiento contextualizado a los jóvenes y no reducir el aprendizaje a la realización de diagnósticos, sino avanzar en marcar directrices para la transformación de situaciones de gestión interna o externa de la comunicación.

Con el andar del Seminario, se sumó la posibilidad de elegir, además de los temas del programa, participativamente algunos de los temas de gestión a trabajar de acuerdo a las expectativas de los estudiantes, y de las temáticas de agenda pública convertidas en preocupaciones para el campo de la comunicación. Esto último hoy es parte de la identidad de la materia conocida en el boca a boca como "Seminario de Comunicación a la Carta".

\section{Una caja de herramientas y lo modos de Decir/ Hacer/Aprender}

El Seminario propone un diálogo entre los textos y los autores, que busca recuperar conceptualizaciones que aporten a la construcción de un marco teórico de la comunicación estratégica. Durante el mismo se trabaja colectivamente en la construcción de una lupa para abordar la problemática organizacional desde la diversidad. Durante ese camino se discute y se confrontan miradas, y en ese debate se evidencia una mayor apropiación de los conceptos que permitan intervenir en problemáticas comunicacionales específicas.

Es un objetivo del Seminario, que los estudiantes puedan identificar la dimensión comunicativa como objeto de estudio y campo de acción para transformar.

En este sentido, la comunicación estratégica es considerara esencialmente un fenómeno relacional más que informacional, y en base a ello en las organizaciones el verdadero desafío es reconocer las huellas de las racionalidades presentes y ponerlas en encuentro en un proyecto compartido. 
REVCOM | ISSN 2451-7836 | Año 4, \#8 | mayo de 2019 | Dossier temático | e004

La perspectiva estratégica es abordada alejada de los modelos administrativos que la equiparan a la planificación estratégica. La comunicación estratégica no se reduce al seguimiento de los momentos de la planificación estratégica, sino que es el esfuerzo de construcción de una perspectiva, una forma de comprender/hacer en la gestión de la comunicación. Allí reside la dificultad en la construcción de herramientas para su aprendizaje, ya que necesita del desarrollo de procesos cognitivos que vayan tomando profundidad en espiral para el análisis integral y eso no se desarrolla únicamente siguiendo un método, sino también realizando ejercicios de cambio de perspectivas de las cosas, sujetos y vínculos buscando romper con los paradigmas lineales que direccionan el accionar comunicacional.

Desde allí se piensa la comunicación estratégica como un modelo mental que acompaña la acción del profesional y re define el concepto de comunicación organizacional dejando de pensarla desde su lugar final de transferencia, para pensarla como un atravesamiento de la organización porque la comunicación "es su forma de relación, la manera en que cada organización trata con sus miembros, se vincula con la sociedad y con las otras instituciones con las que interactúa." (Massoni: 2007)

En este marco, retomamos el concepto de organización desde Fernando Flores y acordamos en pensar a las organizaciones como "el producto de nuestras conversaciones sobre cómo tendremos conversaciones acerca del contexto social - institucionales, oficinas, reglamentos, etc.- dentro del cual sostenemos conversaciones". (Flores: 1997, p.21)

Se retoman también las nociones sobre las dimensiones vinculadas a la gestión de la imagen organizacional, intentando romper con la idea de imagen corporativa, que alude a la creación individual que realizan los públicos sobre la organización.

Desde el Seminario se concibe la imagen como una instancia de encuentro entre la organización y los actores, en base a la cual éstos construyen su mapa mental a partir de los deseos y necesidades puestos en juego. Esta idea es una llave para poder acompañar a los estudiantes a que puedan correrse de la mirada tradicional funcionalista arraigada sobre todo en los esfuerzos comunicacionales empresarios donde siguen imperando formas de hacer que no reconocen los sentidos, intereses y necesidades reales de los actores vinculados a la organización.

Pensar de otra manera la imagen, es comenzar a hacer distinto, es pasar de una instancia de creación individual surgida a partir de la emisión de mensajes organizacionales, 
REVCOM | ISSN 2451-7836 | Año 4, \#8 | mayo de 2019 | Dossier temático | e004

para ser una construcción que surge de la vinculación y está atravesada por la matriz sociocultural del individuo en tanto sujeto social.

Cabe aclarar que esta Caja de Herramientas es abordada desde la mirada del paradigma de la complejidad, por lo cual se entiende que los seres humanos son considerados seres complejos, actores sociales atravesados por cuestiones culturales, que están en constante vinculación entre ellos y con el entorno, y esta vinculación nada tiene que ver con relaciones informacionales lineales, sino que por el contrario se basa en el encuentro entre diferentes racionalidades.

Puede decirse que esta caja de herramientas o modo de mirar está siempre en permanente construcción porque son en sí mismos una experiencia de aprendizaje que se va completando de sentido año a año, y en ella van dejando su huella cada uno de los más de 500 asistentes que han participado en ella.

Desde el origen en el Seminario se repensó la gestión de la comunicación en las organizaciones, lo que demandó revisar en paralelo el estudio de los temas de gestión en la propia formación en comunicación y también la valoración positiva del tránsito por materias como Comunicación Institucional I y II donde se sentaron las bases de la pedagogía de la Comunicación Estratégica aplicada a una gestión de la comunicación compatible y posible con la actualidad de las organizaciones.

Cabe aclarar que en la década del 90, si bien la comunicación estratégica en nuestros campos era una preocupación en términos teóricos, en la mayor parte de experiencias de comunicación en las organizaciones imperaban los modelos de comunicación funcionalista. .

En este contexto, brindar espacio para discutir las producciones de Prieto Castillo y Washington Uranga que comenzaban a plantear el desafío de formar profesionales capaces de descubrir la dimensión comunicativa como una esencia constitutiva en las organizaciones, ayudó a des-focalizar la antigua discusión sobre el rol del comunicador y sus incumbencias, para avanzar en una mirada más profunda e interesante, diversa y específica de la comunicación como motor de cambio social.

En esta línea abordamos inicialmente la conceptualización de estrategia trabajando la visión relacional, aquella que se centra en "una nueva teoría estratégica menos geométrica y más hermenéutica, menos racional y más relacional" (Perez: 2012, p. 75). En el Seminario, la comunicación organizacional deja de ser un instrumento para transformarse en un proceso que 
REVCOM | ISSN 2451-7836 | Año 4, \#8 | mayo de 2019 | Dossier temático | e004

reconoce las diferentes visiones de los actores involucrados, y el desafío del futuro profesional es ponerlas en encuentro.

El Seminario se centra en el planteamiento de la complejidad, se trabajan los temas clásicos de la gestión pero desde la mirada estratégica, haciendo hincapié en el reconocimiento de los actores presentes en cada situación y a partir de este reconocimiento desarrollamos productos comunicaciones CON los actores y no soportes PARA ellos.

Valen de ejemplo la utilización de gabinetes en situación, conversatorios, análisis de trayectorias organizacionales y prácticas de entrenamiento de voceros como herramientas para la pedagogía de la gestión estratégica de la imagen en las organizaciones aplicada a distintas dimensiones tales como la Gestión de Relaciones con la prensa, la cual se focaliza en la creación de un vínculo con este actor estratégico, y en base a ello se analizan diferentes instancias de encuentro que sean capaces de ayudar a las organizaciones a vincularse con los periodistas.

Del mismo modo, en el módulo de Comunicaciones de Crisis, las situaciones de conflicto que pueden afectar a las organizaciones son analizados bajo una mirada prospectiva, donde se reconocen las múltiples facetas de la situación y se incluyen las lógicas presentes para generar acciones que sean capaces de eliminar las causas-efectos reduccionistas. Para ello abordamos metodologías de generación de escenarios y para los actores involucrados en cada uno de ellos, en gabinetes en situación, ensayamos diferentes dispositivos de comunicación.

Remarcamos que el modo de abordar la gestión de la comunicación desde la lógica propuesta recupera la esencia compleja de las organizaciones, proponiendo una mirada integral, y de análisis sincrónico, obviamente historizando la naturaleza de los intereses y problemas. Esa lupa no se detiene en la tradicional mirada de interior y exterior institucional, sino que intenta identificar miradas de dimensiones transversales, en las que se encuentran y se desencuentran una variedad de actores, que poseen relaciones diversas con el problema.

En cuanto a la comunicación hacia el interior de las organizaciones, desde el Seminario se brinda importancia a identificar los rasgos culturales, las vivencias, las preocupaciones y las visiones compartidas para incorporarlas en las estrategias de comunicación para mejorar las organizaciones.

Para gestionar desde lo estratégico es necesario desandar los nudos de la crisis, aceptar los puntos de vistas que chocan y las derivas, que la mayoría de las veces producen traumas organizacionales que van impidiendo el correcto funcionamiento de las organizaciones de 
REVCOM | ISSN 2451-7836 | Año 4, \#8 | mayo de 2019 | Dossier temático | e004

acuerdo a sus objetivos. Solemos decir que en el andar organizacional, y en las funciones rutinarias de los actores, en ocasiones las estructuras se olvidan de para qué fueron hechas. Bregar por la flexibilidad de los modelos y el constante autoanálisis es una de las formas para crear espacios de trabajos que respondan a las necesidades actuales y a contextos inciertos.

En palabras de Morin se considera que "estamos frente a sistemas extremadamente complejos en donde la parte está en el todo y el todo está en la parte. Esto es válido para la empresa que tiene sus reglas de funcionamiento $y$, en cuyo interior, juegan las leyes de la sociedad en su totalidad" (Morin: 2011, p. 125).

En conclusión, todos los componentes de la comunicación organizacional tienen el mismo valor, tanto en los procesos de análisis como en las instancias de planificación participativa. Es por esto que es necesario estudiarlos en movimiento, recoger y poner en común las miradas para que las soluciones a los problemas, y los planes y proyectos sean una construcción que incorpore la mirada de todos los actores.

\section{Algunos logros, desafíos y nuevas realidades}

Después de casi una década y media puede decirse que enseñar comunicación estratégica es un desafío en sí mismo, porque implica desde el principio romper paradigmas acerca del espacio situado de los actores, la construcción conjunta de sentidos, pero también la disputa entre ellos y las dificultades de cómo estas nuevas maneras de hacer rompen con las lógicas de las organizaciones educativas tradicionales.

El espacio pedagógico que busca abordar la comunicación desde la perspectiva estratégica debe plantearse inicialmente como un espacio estratégico. De esta manera, el espacio áulico debe transformarse desde su propio ser ya que tal como establece Fernando Flores "no podemos separar la educación de las prácticas" porque ambas implican una "transformación ontológica, estamos hablando de un cambio de estilo. El ser humano deja de ser este individuo cartesiano de la pregunta interior, y se abre a un ser que tiene conciencia de ser un espacio de transformación." (Flores: 1997, p.11).

Esta transformación es la que propiciamos en el Seminario, desarrollando encuentros donde se trabaja desde el reconociendo de las particularidades y desde allí se busca un lugar común en el cual nos proponemos vincular a los alumnos en tanto actores sociales, en una labor conjunta. Existe una convicción que la comunicación estratégica es una manera de ver, una forma de abordaje, que implica moverse en los bordes conceptuales rompiendo los límites 
REVCOM | ISSN 2451-7836 | Año 4, \#8 | mayo de 2019 | Dossier temático | e004

de la mirada simplicadora y reduccionista para analizarlos desde la densidad del abordaje complejo.

Entendemos que esta mirada compleja, es la única posible para poder abordar las organizaciones contemporáneas, organizaciones que están inmersas en un contexto constituido por múltiples interpretaciones y significaciones sociales, en el cual es ilusorio creer que la simple emisión garantiza un sentido unívoco en el receptor.

La incertidumbre, caracterizada por el fin de las causalidades líneales y el surgimiento de nuevas identidades construidas a partir de las confluencias de múltiples intereses, caracteriza al espacio en el cual se desarrollan las organizaciones en la actualidad.

$Y$ es de acuerdo a esto, que se entiende que la comunicación debe ser una instancia de encuentro en la cual se permite escuchar, empatizar y conversar, y a partir de allí ayuda a generar vínculos que reconocen y re valorizan la diversidad. Es allí donde, desde la intervención en la dimensión comunicativa, se trabaja para la transformación y la planificación de nuevos organizaciones coherentes al modo de vincularnos/hacer comunidad y organización/sociedad.

Abordar y trabajar desde el reconocimiento de las diversidades implica poner en juego nuevas herramientas que le permitan a los profesionales analizar, comprender y actuar en el espacio organizacional. Para ello es necesario desde los espacios pedagógicos de la comunicación estratégica, incentivar procesos creativos que acompañen la mirada de viejos problemas y den lugar a soluciones integrales.

En los últimos años el Seminario ha nucleado estudiantes interesados en cambiar la realidad desde la organización, y eso se demuestra en la calidad y compromiso en la cursada, pero particularmente se evidencia en la cantidad de profesionales que se desempeñan en distintas instituciones públicas, sociales y privadas de la ciudad y la región dando curso a proyectos democráticos, innovadores, de mirada multidimensional.

Este camino no es siempre igual, cada año los grupos son distintos, y lo que proponen, debaten o recorren a partir del mismo programa es a veces sorpresivo, otras implica revisar cómo hacer nuevamente. Las primeras semanas de trabajo requieren de mucho esfuerzo para romper con estructuras que permitan correr la mirada. Esa situación a veces es angustiante en los estudiantes de los últimos años de la carrera, pero la experiencia pone en evidencia que ese quiebre es el que permite dar lugar a una mirada más inclusiva, más diversa, que en esencia es la naturaleza de la perspectiva estratégica.

"Pedagogía de la Comunicación Estratégica: una experiencia en construcción" | Analía Chiavassa y Romina Trincheri | https://doi.org/10.24215/24517836e004 | Pág. 7 


\section{VREVCom \\ REVISTA CIENTIFICA DE LA REDCOM}

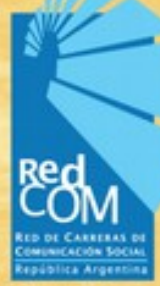

REVCOM | ISSN 2451-7836 | Año 4, \#8 | mayo de 2019 | Dossier temático | e004

Cuando ya se avanza en ese sentido, queda demostrado en los distintos ejercicios de gabinetes en situación, que la caja de herramientas que se va armando solo logra consolidar todas las teorías sólidas del campo ya incorporada en el riquísimo trayecto educativo de la licenciatura en Comunicación Social de Rosario, que posee una fuerte identidad basada en su convivencia en la misma facultad con la Lic. en Trabajo Social, Ciencia Política, Relaciones Internacionales y la reciente incorporación de Turismo.

Además el Seminario dialoga con otras instancias de aprendizajes optativos y de investigación, se enriquece de ellos, y hace de amalgama de todas esas influencias siempre orientados a fortalecer un ser profesional sensible y motor de transformación de la sociedad.

Hoy las organizaciones se enfrentan a nuevas realidades que requieren dinamismo, el desarrollo de comunidades virtuales, el surgimiento de diversas identidades sociales, y la problematización social de temáticas antes consideradas de algunos sectores, las obligan a buscar una nueva forma de vincularse con sus públicos.

Todas las preocupaciones/problemas que enfrentamos como sociedad deben ser incluidas y debatidas en los nuevos modelos de organización, y la comunicación es clave para generar cambios y consensos que permitan generar esos nuevos modos de hacer más respetuosos.

Las clases del Seminario están enfocadas en estas cuestiones, no brindando recetas inflexibles sino soluciones colectivas basadas en estrategias que recuperen las miradas de los múltiples actores.

Y este compromiso implica tomar una postura, involucrarse y gestionar en concordancia con esto, porque son problemáticas transversales que cruzan todas las relaciones con sus públicos estratégicos (empleados, clientes, proveedores, opinión pública, etc), y es esencial tener en cuenta sus intereses y necesidades específicos para vincularse con ellos.

Esta realidad compleja, densa, en contante reconfiguración, no puede ser abordada generando comunicados ni difundiendo información, porque estas viejas formas aprendidas no son útiles para dar cuenta del entrelazamiento de sentidos

Es por ello, que como quedó expresado en este texto, el desafío constante del seminario es ayudar a los alumnos a abandonar las certezas que nos brinda el modelo informacional, y acompañarlos en el camino de descubrir la riqueza del pensamiento estratégico.

Como continuidad de esta mirada, en el espacio de las organizaciones, buscamos problematizar sobre el espacio estático y estanco que la comunicación ocupa en la estructura 
REVCOM | ISSN 2451-7836 | Año 4, \#8 | mayo de 2019 | Dossier temático | e004

de muchas de ellas ya que entendemos que esto la reduce a una visión funcional y la circunscribe a tareas informacionales. Por el contrario, entendemos que la comunicación debe atravesar a toda la organización como una forma de gestión basada en el diálogo, y la labor del profesional es generar los espacios para este encuentro, involucrándose en el proceso de significación dialógico.

Hoy más que nunca en la era de la pos verdad, en escenarios complejos donde los hechos manifiestan que convivimos en una sociedad donde distintas formas de pensar y hacer muestran una puesta en crisis paradigmática que genera tensiones y desconcierto es necesario buscar camino para que de la diversidad puedan establecerse nuevos modos de generar comunidad.

Es tiempo de asumir responsabilidades desde las organizaciones que construyen los pueblos, las ciudades en las que vivimos. Desde la gestión de la comunicación podemos visibilizar a los actores o aportar a su sumisión. En este sentido cuando hablamos de estrategias no pensamos en herramientas frías, sino en la construcción de soluciones colectivas. Cómo hacerlo, es la pregunta que nos hacemos en cada edición del Seminario.

\section{BIBLIOGRAFÍA}

Alvarado, M. (2006). Paratexto. Buenos Aires: Eudeba.

Ducrot, O. (2000). "La elección de las descripciones en semántica argumentativa léxica". Revista Iberoamericana de Discurso y Sociedad, 2 (4), pp. 23-45.

Flores, Fernando (1997).Creando organizaciones para el futuro: Chile. Dolmen Ediciones

Massoni, S. (2007) "Tres movimientos y siete pasos hacia una comunicación estratégica integral". En Estrategias. Los desafíos de la comunicación en un mundo fluido. Rosario: Homo Sapiens Ediciones.

Morin, Edgar (2011). "La epistemología de la complejidad", "La complejidad en la empresa". En Introducción al Pensamiento Complejo. España: Gedisa

Ortiz, R. (2002). "Globalización/mundialización". En Altamirano, C. (ed.) Términos críticos de sociología de la cultura (pp. 105-111). Buenos Aires: Paidós.

Pérez Bergliaffa, M. (2012). "El artista y sus obras con fantasmas. Entrevista a Christian Boltanski". Revista de Cultura $\tilde{N}$ [en línea]. Consultado el 28 de octubre de 2013 en <http://www.revistaenie.clarin.com/arte/Christian-Boltanski-Buenos-Aires_0_789521222.html>.

Pérez, Rafael Alberto. (2012) Pensar la estrategia. Buenos Aires: Lcrj'Apero. 


\section{$\bigcup_{\text {REVCOm }}$ \\ REVISTA CIENTIFICA DE LA REDCOM}

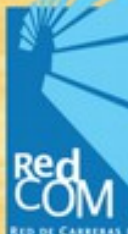

REVCOM | ISSN 2451-7836 | Año 4, \#8 | mayo de 2019 | Dossier temático | e004

Schvarstein, Leonardo (1998). “Introducción”. En Diseño de Organizaciones. Tensiones y Paradojas. Buenos Aires.

Uranga, Washington (2002). "Gestionar desde la comunicación - gestionar procesos comunicacionales". Oficios Terrestres; no. 11-12

Artículo recibido el 15-03-2019 | Evaluado y aprobado por el Comité Editorial el 10-04-2019 | Publicado 26-05-2019

http://perio.unlp.edu.ar/ojs/index.php/revcom/ Esta obra está bajo una Licencia Creative Commons Atribución-NoComercial-SinDerivar 4.0 Internacional 